\title{
Evolving Patterns of Cryptosporidiosis: Issues and Implications in the Context of Public Health in India
}

\author{
Bijay Ranjan Mirdha ${ }^{{ }^{*}}$ \\ ${ }^{1}$ Department of Microbiology, All India Institute of Medical \\ Sciences, New Delhi, India
}

Ann Natl Acad Med Sci (India) 2021;57:81-93.

\begin{abstract}
Address for correspondence Bijay Ranjan Mirdha, MD, FAMS, Department of Microbiology, All India Institute of Medical Sciences, New Delhi 110029, India (e-mail: mirdhabr@hotmail.com).
\end{abstract}

\begin{abstract}
Keywords

- Cryptosporidium species

- subtyping

- epidemiology

- molecular prospecting

- India

Cryptosporidiosis is one of the major causes of diarrhea in immune-compromised individuals and children besides causing sporadic water-borne, food-borne, and zoonotic outbreaks. In 2016, Cryptosporidium species infection was the fifth leading cause of diarrhea and acute infection causing more than 4.2 million disability-adjusted life years lost besides a decrease in childhood growth. Human cryptosporidiosis is primarily caused by two species/genotype: Cryptosporidium hominis (anthroponotic) and Cryptosporidium parvum (zoonotic) besides other six rare species/genotypes. Transmission intensity, genetic diversity, and occurrence of genetic recombination have shaped the genus Cryptosporidium population structures into palmitic, clonal, and epidemic. Genetic recombination is more in C. parvum compared with C. hominis. Furthermore, parasite-host co-evolution, host adaptation, and geographic segregation have led to the formation of "subtype- families." Host-adapted subtype-families have distinct geographical distribution and host preferences. Genetic exchanges between subtypes played an important role throughout the evolution of the genus leading to "adaptation introgression" that led to emergence of virulent and hyper-transmissible subtypes. The population structure of $C$. hominis in India appears to be more complex where both transmission intensity and genetic diversity are much higher. Further, study based on "molecular strain surveillance" has resulted newer insights into the epidemiology and transmission of cryptosporidiosis in India. The identification at the species and genotype levels is essential for the assessment of infection sources in humans and the public health potential of the parasite at large. The results of the study over three decades on cryptosporidiosis in India, in the absence of a national surveillance data, were analyzed highlighting current situation on epidemiology, genetic diversity, and distribution particularly among vulnerable population. Despite creditable efforts, there are still many areas need to be explored; therefore, the intent of this article is to facilitate future research approaches for mitigating the burden associated with this disease.
\end{abstract}

\footnotetext{
${ }^{*}$ Recipient of Dr. Pran Nath Chhuttani oration.
}

published online May 3, 2021
DOI https://doi.org/ 10.1055/s-0041-1726149 ISSN 0379-038X.
(C) 2021. National Academy of Medical Sciences (India).

This is an open access article published by Thieme under the terms of the Creative Commons Attribution-NonDerivative-NonCommercial-License, permitting copying and reproduction so long as the original work is given appropriate credit. Contents may not be used for commercial purposes, or adapted, remixed, transformed or built upon. (https://creativecommons.org/licenses/by-nc-nd/4.0/). Thieme Medical and Scientific Publishers Pvt. Ltd. A-12, 2nd Floor, Sector 2, Noida-201301 UP, India 


\section{Introduction}

Cryptosporidium species, a protozoan parasite, infects the epithelial cells of the intestinal tract of humans and a variety of animals worldwide and one of the major causes of diarrheal disease in humans globally. Cryptosporidium species, which belongs to the phylum Apicomplexa, was first described as a cell-associated organism in the gastric mucosa of mice in 1907 by E.E. Tyzzer. ${ }^{1}$ The genus Cryptosporidium was named so because of the absence of sporocysts within the oocysts, a unique difference from other coccidian parasites. This genus did not receive much attention for almost 70 years, till two simultaneous reports of human cryptosporidiosis were published in 1976, one in an apparently healthy individual and other in an immune-compromised person. ${ }^{2,3}$ These two reports also set the tune of uniqueness of Cryptosporidium species that it can infect both immune-competent and immune-compromised. With the emergence of human immunodeficiency virus (HIV) infection and acquired immunodeficiency syndrome (AIDS) pandemic, the incidence of cryptosporidiosis was increasingly recognized as the cause of severe life-threatening diarrhea in children as well as in immune-compromised individuals. In humans, immune-competent individuals usually experience self-limiting diarrhea. The self-limiting disease is often manifested by acute profuse watery diarrhea accompanied by abdominal pain and other enteric symptoms including vomiting, low grade fever, general malaise, weakness, fatigue, loss of appetite, nausea, chills, and sweats. ${ }^{4}$ In contrast, immune-compromised individuals, particularly those with HIV infection and other immunodeficiency disorders, often suffer from intractable diarrhea. Immune-compromised individuals predisposed to cryptosporidiosis includes HIV seropositive individuals with decreased CD4+ T cell count, patients with malignant disorders undergoing chemotherapy, T cell deficiency disorders like severe combined immunodeficiency, and hyper-immunoglobulin $M$ syndrome, transplant recipients. ${ }^{5}$ Diarrhea tends to be much more severe in hosts having defects in either cell-mediated or humoral immunity. In a study of HIV patients, fulminant cryptosporidiosis occurred with CD4+ T cell count less than 50 cells/ $/ \mathrm{L}^{6}{ }^{6}$ Extraintestinal cryptosporidiosis has also been reported causing pancreatitis, sclerosing cholangitis, cirrhosis, cholangiocarcinoma, and respiratory involvement. ${ }^{7}$ of late, Cryptosporidium species were recognized as one of the important cause of diarrheal illness in children younger than 5 years of age with peak occurrence in children below 2 years of age. ${ }^{8}$ Nosocomial infection by direct and indirect person-to-person transmission has also been well documented, causing secondary cases among roommates and family members. ${ }^{9}$ Animal-to-person (zoonotic) transmission primarily occurs among veterinarians and veterinary students as well as other people exposed to live stocks. Preweaned calves are considered to be an important source of zoonotic cryptosporidiosis. ${ }^{10}$

Cryptosporidium species has a complex asexual (merogony) and sexual life cycle and the lifecycle is completed within the epithelial cells of small intestine and colon of the infected hosts with the developing stages present on luminal surface. Asexual and sexual reproduction of the parasite occurs within the extra-cytoplasmic vacuole. This results in production of merozoite that eventually infect the adjacent epithelial cells leading to generation of both thin and thick-walled sporulated oocysts containing sporozoites. Sporozoites released from them infect the epithelial cells. Thick-walled oocysts excreted from infected individual are the infective stage and can survive for many months in temperate and moist conditions, and are resistant to many common disinfectants, particularly chlorine-based disinfectants. ${ }^{11}$ Transmission occurs principally through the fecal-oral route, following direct or indirect contact with Cryptosporidium oocysts. The oocyst is responsible for the dissemination of the infection. It is of small size (4-8 $\mu \mathrm{m})$; size may vary with different species and is environmentally robust. ${ }^{12}$ A single oocyst is sufficient to produce infection and disease in susceptible hosts. ${ }^{13}$ The infective dose is variable for different strains. The infective dose is 9 oocysts for TAMU, 87 for Iowa, and 1,042 for UCP strains. ${ }^{14}$ Infected hosts act as reservoirs, allowing the propagation of the infection. It is now recognized that the infectious dose as well as the duration and severity of illness are influenced by both etiological factors that include the species and strain of the parasite, as well as various host factors (age and immune status). Depending on the parasite species and the host's immune competency, the prepatent period (time between infection and active oocyst shedding) is between 1 and 3 weeks, whereas the patent period (duration of oocysts shedding) can range from several days to months or years ${ }^{15}$ and such long patency can lead to persistent infection and diarrhea. There are more than 38 known and few unnamed Cryptosporidium species, of which Cryptosporidium hominis (C. hominis) and Cryptosporidium parvum (C. parvum) are the two most common species that are responsible for nearly $90 \%$ of human infections. C. hominis is restricted to humans, whereas $C$. parvum can infect other mammals. Other six (6) species that have been associated with human infections include $C$. meleagridis, $C$. felis, $C$. canis, $C$. viatorum, C. muris, C. suis, C. andersoni, and C. corvine ${ }^{16} C$. hominis and C. parvum differ in their host range, genotype, and pathogenicity. The burden of disease from cryptosporidiosis varies substantially between and within countries/areas. Some of the accumulating data have suggested that there can be variations in the clinical manifestations of cryptosporidiosis according to the infecting Cryptosporidium species/genotype or subtypes. ${ }^{17,18}$ Three major clinical presentations in immune-competent individuals include asymptomatic carriage, acute diarrhea, and persistent diarrhea. The incubation period may vary from 3 to 14 days and the illness is usually self-limiting. ${ }^{19}$ Other symptoms include malaise, fatigue, anorexia, pyrexia, abdominal pain, nausea, vomiting, and weightloss. ${ }^{20}$ Oocysts may continue to be shed in the feces following cessation of diarrhea for 7 days (range: 1-15 days). The clinical presentation of cryptosporidiosis leads to severe diarrhea in immune-compromised individuals.

Tinctorial stains such as auramine-phenol, safranin, and modified acid-fast staining methods are commonly used to detect Cryptosporidium oocysts in fecal specimens. However, 
these staining techniques, although cost-effective and specific, have been reported to be relatively less sensitive compared with immunoassays and polymerase chain reaction based assays. ${ }^{21}$ With the limited availability of the treatment options, control of the disease relies mainly on the knowledge of the biology and transmission of the different species of Cryptosporidium. ${ }^{11}$

Since the first report of human cryptosporidiosis in India, ${ }^{22}$ human cases have continued to increase underpinning many newer aspects and insights with promising progress. The present analyses describe the trend of laboratory confirmed human cryptosporidiosis in India over a period of more than three decades and focuses on source of infection, mode of transmission, risk factors, and distribution of the disease and genetic characteristics of Cryptosporidium species in different parts of the country.

\section{Materials and Methods}

There has been a significant addition of literature to the incidence and prevalence of human cryptosporidiosis in India. Laboratory confirmation using microscopy or by molecular methods was used to meet the case definition for cryptosporidiosis. A systematic search about all relevant published abstracts and full texts published in English language on human cryptosporidiosis before January 2020 was conducted and all research articles were analyzed. All the selected research articles were classified under following contents such as (a) number of publications per year, (b) state-specific studies, and (c) different aspects of cryptosporidiosis. Various demographics such as age, sex, clinical manifestations (diarrhea, weight loss, etc.), laboratory diagnosis and genotype(s), and subtype(s) association were studied in detail.

\section{Results and Discussion}

Based on the search strategy, nearly hundred published reports from different parts of the country addressing relevant information associated with Cryptosporidium infections in India were included. Based on number of publications per year, annual publication frequency was determined. From 1990-2001 to 2010, publication was higher mostly reporting about prevalence and thereafter some thematic papers with particular concepts along with study on molecular aspects brought the new knowledge and insight about cryptosporidiosis.

\section{Human Cryptosporidiosis}

Cryptosporidium's unusual location within the host cell, sequestered between the cell cytoplasm and cell membrane, its ability to autoinfect through "thin walled" oocysts within the intestine, its innate antimicrobial resistance, and general lack of host specificity (especially in C. parvum) are some of the unique features that distinguish it from other enteric protozoa.

\section{Prevalence of Cryptosporidiosis}

Prevalence rate of Cryptosporidium infection ranges from less than $1 \%$ to more than $30 \%$ worldwide. The prevalence of
Cryptosporidium species in humans is reported to be 0.3 to 4.3\% in North America, 0.1 to $14.1 \%$ in Europe, 1.3 to $13.1 \%$ in Asian countries, 2.6 to $21.3 \%$ in African countries, 3.2 to $31.5 \%$ in central and South American countries. ${ }^{23}$ Studies have shown that cryptosporidiosis is more common in developing countries ( $5 \%$ to $>10 \%$ ) than in developed countries $(<1-3 \%){ }^{11,24}$ According to the US surveillance of cryptosporidiosis (2009-2010), the rate of reported cases was 2.5 and $2.9 \%$ per 100,000 populations in 2009 and 2010 respectively. ${ }^{25}$ In England and Wales, an average of 4500 laboratory identified cases were reported each year since 1998 to $2008 .^{26}$ The reported prevalence of $C$. hominis is more than $C$. parvum in the developing world including India, ${ }^{27,28}$ whereas $C$. parvum has been reported to be the prevalent species in western countries and also in many of the middle eastern countries including Kuwait (94\%), Iran (74 and 75\%), and Jordan (50\%). ${ }^{29}$ In India, variable prevalence was observed in different studies and in different populations, such as HIV-positive and negative adult patients with diarrhea, children under 5 years of age with acute and persistent diarrhea, and other groups such as in cancer patients and transplant recipients.

\section{Geographical and Seasonal Distribution}

Epidemiologic surveys indicate that human cryptosporidiosis is distributed worldwide both in urban and rural populations. ${ }^{30}$ Geographic differences that exist in the disease burden are attributable to distribution of $C$. hominis and $C$. parvum. $C$. hominis has been shown to be more prevalent in North and South America, Australia, Japan, Africa, and other developing countries, ${ }^{27}$ suggesting that the anthroponotic transmission is of greatest importance in these regions. However, C. parvum is the predominant species in United Kingdom, Northern Ireland, France, Switzerland, Portugal, Slovenia, Czech Republic, and New Zealand. ${ }^{10}$ The seasonal differences in the distribution of cryptosporidiosis have been described from various regions of the world that also vary with geographical locations. It has been observed that $C$. hominis is highly prevalent in autumn in the United Kingdom and New Zealand, whereas C. parvum is more prevalent during spring in Canada, Ireland, and the Netherlands. This is believed to be related to increased exposure to animal oocysts following the calving and lambing season for C. parvum, as well as to increased travel, exposure to water, and attendance at day care centers for C. hominis. ${ }^{10}$ In China, it has been observed that increase in temperature and precipitation was considered to be associated with an increase in the incidence of cryptosporidiosis. It was also observed that in moist tropical climates, precipitation was a strong seasonal driver for cryptosporidiosis; in contrast, in temperate climates, the incidence of cryptosporidiosis peaked with the increase in temperature. ${ }^{31}$ In India, the incidence of cryptosporidiosis among children residing in the more temperate northern parts of India correlated positively with temperature and negatively with humidity, but correlations were not observed for children residing in the more tropical southern region. ${ }^{18}$ Effect of climate and meteorology on cryptosporidiosis was studied by Jagai et al, ${ }^{31}$ who developed 
a meta-analysis framework to assess the link between environmental exposure to protozoa via drinking and recreational water and cryptosporidiosis infection. The study observed a marked increase in cryptosporidiosis infection during warm and rainy seasons. Regardless of above report, the seasonal patterns and distributions are incomplete and remain to be studied extensively to explore transmission dynamics of this disease.

\section{Cryptosporidiosis in Vulnerable Groups}

1. Cryptosporidiosis in HIV-infected adults

Cryptosporidiosis is one of common opportunistic infections among immune-compromised individuals. The prevalence of cryptosporidiosis in HIV-infected patients with diarrhea has been reported to differ in range depending on the population studied, degree of immune-suppression, and use of antiretroviral therapy (ART). Reports on the prevalence of cryptosporidial diarrhea in HIV infected adults from different parts of India from the mid-1990s have ranged from 0.7 to $83 \%$ in symptomatic and from 1.4 to $57 \%$ in asymptomatic individuals. ${ }^{32,33}$ In a study conducted between March 2002 and March 2007 at National AIDS Research Institute, Pune, India, by Kulkarni et al, ${ }^{34}$ intestinal parasites were detected in $35 \%$ of the HIV infected patients, of which $12 \%$ (16 of 137) were infected with Cryptosporidium species. Vignesh et $\mathrm{al}^{35}$ reported an overall prevalence of $2.9 \%$ of Cryptosporidium in HIV-infected patients between 2003 and 2006 from Southern India. The prevalence percentage in HIV infected patients from other parts of India is 20\% (9/45) from Kashmir, ${ }^{36} 19 \%$ (19/100) from Ahmedabad, ${ }^{37} 17.2$ (7/43) and 20.6\% (7/34) from New Delhi, ${ }^{38,39}$ $25 \%$ (28/111) from Vellore, ${ }^{28} 28.7 \%$ (23/80) from Madurai, ${ }^{40}$ 9.64\% (32/332) from Maharashtra, ${ }^{41}$ and 39.8\% (146/366) from Varanasi. ${ }^{42}$ In some of North Eastern states, the prevalence of Cryptosporidium in HIV-infected people was reported to be higher than $70.0 \%,{ }^{43}$ though the study had included very small number of patients. The results of many of these studies have indicated that HIV-infected individuals had a low CD4+ cell count in almost $50 \%$ of cases. The species $C$. hominis and C. parvum were primarily responsible for cryptosporidiosis in HIV-infected patients in our country. Others species that have been confirmed as human pathogens in HIV patients in India are $C$. meleagridis ${ }^{28,44}$ and $C$. viatorum. ${ }^{45}$ A comparatively large proportion of individuals infected with $C$. meleagridis have been observed in Haiti ${ }^{46}$ and Peru. ${ }^{47}$ Some of the relatively recent studies on HIV infected patients also showed similar trend with reference to cryptosporidiosis. ${ }^{48,49}$ Asymptomatic cryptosporidial infection in HIV population is under-appreciated and in few HIV-infected cases extraintestinal manifestations like biliary, pulmonary, and middle ear involvement have been described in AIDS patients..$^{50}$ Introduction of the highly active antiretroviral therapy (HAART) has had a remarkable impact both on reduction in occurrence and clinical course of cryptosporidiosis. In a multinational cohort study of HIV-positive individuals from Australia and 10 European countries, conducted during 1997 to 2001 and 1994 to 1996, showed significant HAART-induced decrease in progression to cryptosporidiosis ( 3.1 to $0.2 \%$ ). ${ }^{51}$ To some extent, similar observations have also been noted in our country.

\section{Cryptosporidiosis in Children}

Cryptosporidium species have been recognized as one of the leading causes of moderate-to-severe diarrhea particularly in children younger than 5 years of age. ${ }^{52}$ Initial studies before 1990 from the country reported increased detection of cryptosporidium from Children. ${ }^{22,53-56}$ These studies were based on staining techniques results. The very first study from Vellore ${ }^{22}$ showed parasite Cryptosporidium in $13.1 \%$ children under 6 months of age with acute diarrhea and in $9.8 \%$ age-matched controls. The study is of significance for the fact that symptomless individuals may get colonized by Cryptosporidium species. Around the same period, study from Calcutta (Present Kolkata), Cryptosporidium was detected as the only pathogen in $18(4.47 \%, 18 / 402)$ children below 9 years of age and diseases were self-limiting. ${ }^{33}$ Subsequently many case reports and series were reported from nearly all parts of the country. ${ }^{55,57,58}$ Stratifying the children as HIV seropositive with and without diarrhea, the reported prevalence is 20 and 14\%, respectively. ${ }^{38}$ Hospital and community-based studies have reported Cryptosporidium as the cause of pediatric diarrhea, in 1.3 to $18.9 \%$. A prevalence rate of $67 \%$ has been reported by Sarkar et al in children belonging to a semiurban community in southern India ${ }^{59}$ and $27 \%$ by enzyme-linked immunosorbent assay in a study conducted in Delhi. ${ }^{60}$ In developing countries, prevalence of Cryptosporidium in diarrheal children under 5 years reflect both exposure and immunity. Mortality in children under 5 years of age in developing countries due to cryptosporidiosis is 30 to $50 \%{ }^{61}$

Besides $C$. hominis, $C$. felis and $C$. parvum (mouse genotype) have been reported from India. ${ }^{28} C$. meleagridis $1 / 35(2.9 \%)$ and C. muris $1 / 35$ (2.9\%) have also been detected in Saudi Arabia. ${ }^{62}$ Differences in the distribution of Cryptosporidium genotypes in humans are considered as an indication of differences in infection sources. Detection of $C$. parvum in some populations has been considered to be the result of zoonotic transmission but recent subtyping studies have shown that not all C. parvum infections in humans are the result of zoonotic transmission. Among the $C$. parvum GP60 subtype families identified, alleles IIa and IIc are the two most common types. The former has been identified in both humans and ruminants, whereas the latter has been seen only inhumans. ${ }^{63}$ Asymptomatic cryptosporidiosis in children in India has been reported within a range of 0 and $9.8 \%$. These findings emphasize the lack of correlation between disease severity or symptoms and Cryptosporidium infection that may persist beyond the clinical illness. Community-based studies in India are lacking, and differences between rural and urban population have not been studied intensively and extensively except two studies. ${ }^{57,59}$ Generally, people living in rural areas are expected to have higher prevalence of Cryptosporidium related to poor sanitation conditions in most of rural areas, a lack of necessary general health knowledge, and health habits of people.

In contrast to many studies related to childhood cryptosporidiosis, persistent diarrhea due to cryptosporidiosis and malnutrition have been increasingly reported from Africa. ${ }^{64}$ The exact degree to which malnutrition and diarrhea are associated with cryptosporidiosis is not known; 
however, they are assumed to have a complex bidirectionalrelationship. ${ }^{65}$ Notably, a correlation between early childhood cryptosporidiosis and growth reduction or even failure has been identified particularly in children younger than 12 months, in addition to long-term cognitive deficits and impaired physical fitness later in life. ${ }^{66,67}$ Only study from India has shown association between malabsorption and coccidian parasites. ${ }^{68}$

\section{Cryptosporidiosis in Transplant Recipients}

Reports of cryptosporidiosis prevalence varied widely depending on the non-HIV population examined. Enteric infections in 65 patients undergoing bone marrow transplantations (BMT) with diarrhea were studied. ${ }^{69}$ Enteric pathogens were found in $60 \%$ of patients beforeorafter transplantations.Cryptosporidium species did contribute significantly to morbidity besides many bacterial and rotavirus infections in this study. Cryptosporidial infection was first reported in a renal transplant patient by Weisburger et $\mathrm{al}^{70}$ in 1979. In India, 60 living renal transplant recipients were examined, of which 12 patients $(20 \%)$ had cryptosporidium oocysts including $16.6 \%$ who had symptomatic diarrhea. Patients responded well to spiramycin $(2 \mathrm{~g} /$ day for 10 days). ${ }^{71}$ In a retrospective analysis, it was observed that 9\% (119/1235) renal transplant recipients developed diarrhea, and Cryptosporidium was found in 34/119 (28.5\%). Nine of $680(1.3 \%)$ patients were on a cyclosporine (CSA)-based regimen, and 25/643 (3.8\%) patients were on a tacrolimus (Tac)based regimen. It was observed that relative risk of developing Cryptosporidium infection was lower on the CSA-based regimen, compared with the Tac-based regimen (odds ratio: 0.35, $95 \%$ confidence interval: $0.17-0.72, p=0.003$ ). Patients with Tac and mycophenolate mofetil combination therapy had a significantly high risk of Cryptosporidium infection. ${ }^{72}$ We conducted a study from 38 transplant recipients comprising 29 postrenal, two liver, and seven BMT recipients presenting with diarrhea and 50 transplant recipients (42 postrenal transplant, eight BMT) without diarrhea. Presence of intestinal parasites was examined by light microscopy and multilocus genotyping of Cryptosporidium species was analyzed. Twenty-one percent (8/38) patients were positive for Cryptosporidium species. Multilocus genotyping of Cryptosporidium species detected four isolates of $C$. hominis; two of $C$. parvum, one of mixed genotype, and genotype of one could not be ascertained. All the $C$. hominis isolates were detected in adult postrenal transplant (PRT) recipients, whereas the $C$. parvum isolates included a child with BMT and an adult with PRT $^{73}$ In an another study from Lucknow, 358 renal transplant recipients and 200 healthy controls were examined that showed positivity of $8.4 \%$ (30/358) in former group and none from controls $(p<0.001)$. C. parvum was identified in $(33.3 \%)$ and C. hominis in $20 / 30(66.7 \%)^{74}$

\section{Cryptosporidiosis in Cancer Patients}

Cancer patients often experience transient or constant impairments in immunity due to administration of chemotherapeutic drugs. Prevalence of cryptosporidiosis in cases of malignant disorders in India has been reported to be $0.3^{75}$ and $1.3 \%(7 / 560) .{ }^{76} \mathrm{~A}$ recently published case-control study from
China has shown occurrences of Cryptosporidium species in patients with digestive malignancies before chemotherapy. The infection rates of Cryptosporidium spp. in colorectal, esophageal, liver, and small intestine cancers were $17.24 \%$ (20/116, $p<0.01), 6.25 \%(1 / 6, p<0.029), 14.29 \%(1 / 7, p<0.001)$, and $40 \%(2 / 5, p<0.001)$. All the Cryptosporidium spp. obtained were $C$. parvum, suggesting potential zoonotic transmission. The other notable findings observed were the plausible associations of subtypes IIaA15G2R1 and IIaA15G2R2 in patients with colorectal cancer and IIaA13G2R2 subtype with both colorectal and liver cancers. ${ }^{77}$

\section{Food- and Water-Borne and Respiratory Cryptosporidiosis}

Cryptosporidium has been incriminated in many water-borne outbreaks. There were reports of 19 outbreaks in United Kingdom and United States between 1984 and 1996, affecting an estimated number of 427,100 individuals. By the end of 2016, at least 524 water-borne outbreaks of cryptosporidiosis have been reported globally, including drinking and recreational water. ${ }^{78}$ Cryptosporidium oocysts have been detected in surface water. The commonness of fecal wastes from human and nonhuman hosts suggests that many environments, particularly water and soil, act as vehicles for the spread of the disease. The oocysts have also been identified as contaminations in different types of food, mainly on numerous fresh vegetables and fruits, and at least 26 food-borne outbreaks have been reported worldwide. ${ }^{79}$ In India, no study has been performed till date to ascertain, if at all there are any food and water-borne outbreaks.

Respiratory cryptosporidiosis has been reported in immunocompromised patients as well as in children and was supported by experimental intranasal infection of piglets. The symptoms associated with this route are respiratory (laryngo-tracheitis) and could be accompanied by mild diarrhea. Reports of cryptosporidial infections of the respiratory tract ${ }^{80}$ as well as gastric cryptosporidiosis ${ }^{81}$ among immune-deficient and immune-competent individuals have indicated that this protozoan is not restricted only to the gastrointestinal tract rather exhibits extraintestinal tropism. Two reports of respiratory cryptosporidiosis, one in an adult ${ }^{82}$ and the other in a 10-year-old child, have been reported in India. ${ }^{83}$

\section{Molecular Epidemiology of Cryptosporidiosis}

Despite the high prevalence of cryptosporidiosis in developing countries, genetic characterization of Cryptosporidium species has not been studied extensively in India except few. $18,27,84,85$

\section{Cryptosporidium Species and Their Genotypes in Humans}

Genotyping tools based on DNA sequences of different antigens and housekeeping genes have identified $C$. hominis and C. parvum species primarily responsible for infections in both immune-competent and immune-compromised individuals. ${ }^{86}$ Studies using small subunit ribosomal RNA have revealed presence of $C$. canis, C. felis, and C. meleagridis in 
AIDS patients in the United States, Kenya, Thailand, Peru, and many European countries. ${ }^{87,88}$ Likewise, some putative human $C$. muris infections have been reported from immune-compromised patients from different parts of the world including India. ${ }^{27}$ Similarly, $C$. cervine and $C$. suis have been reported from Canada and United States, respectively ${ }^{89,90}$ Above-mentioned reports signify presence of wide spectrum of zoonotic infections in different geographic regions. Recently $C$. andersoni was identified in a few sporadic cases of cryptosporidiosis and was the predominant species $(79.59 \%, 78 / 98)$ in diarrheal patients from Assam in India. ${ }^{91}$

\section{Subtyping (subgenotyping)}

Thus, molecular methods, besides diagnosis, have also been applied for differentiation of Cryptosporidium at subtype level. ${ }^{86}$ Identification of the isolates at the subtype/subgenotype level is useful for understanding of the population structure of Cryptosporidium species..$^{92}$ One of the popular subtyping tool is the DNA sequence analysis of the variable fragment of the gene encoding a sporozoite surface glycoprotein gp60 (also called cpgp40/15 or gp40). The gp60 gene is similar to microsatellite sequence by having tandem repeats of the serine-coding trinucleotide TCA, TCG, or TCT at the 50 (gp40) end of the gene. However, in addition to variations in the number of trinucleotide repeats, there are extensive sequence differences in the nonrepeat regions, which categorize $C$. parvum and $C$. hominis each to several subtype families. Sequence analysis of gp60 gene is widely used in Cryptosporidium subtyping because of its sequence heterogeneity and relevance to parasite biology. It is the single most polymorphic marker identified so far in the Cryptosporidium genome. gp60 is located on the surface of apical region of invasive stages of the parasite, and is one of the dominant targets for neutralizing antibody responses in humans. ${ }^{93}$ Thus, it is possible to link biologic characteristics of the parasites and clinical presentations with the subtype family identity. Nomenclature of gp60 subtypes starts with the subtype family designation Ia, Ib, Id, Ie, If, etc. for C. hominis, and IIa, IIb, IIc, IId, etc. for $C$. parvum, respectively. Some of the $C$. parvum subtype families, such as Ila and IId, are found in both humans and ruminants. C. parvum subtype type families, especially IIc, have been reported in humans. ${ }^{10,94}$ In an Indian study, ${ }^{95}$ conducted at three different centers (Vellore, Trichy, and Delhi), subtypes Ia and Ie were the most commonly identified subtypes among the $C$. hominis-infected children, followed by subtypes Ib and Id. "If" subtype, however, was reported mainly in Delhi, with only one instance from Vellore. Restriction fragment length polymorphism patterns suggestive of mixed infection with la and If were also reported in one child from the Delhi. Among the seven children with $C$. parvum infection, one each with subtypes IIc and IId was identified in the Delhi. Sequencing and phylogenetic analysis showed the presence of a newly identified subtype, "IIm" in the southern centers, that is, in Vellore and Trichy (numbers T415 and V740), and another previously unreported subtype, named IIn in accordance with current nomenclature conventions, ${ }^{96}$ in the Vellore center (numbers V416 and V640).
However, no significant difference in severity of diarrhea among children infected with $C$. hominis subtypes Ia, Ib, Id, and Ie was noted. A trend toward association of shorter duration of diarrhea with subtype Id than with the other subtypes was observed. Similarly, there was a trend toward association of older age with subtype Ia than with other genotypes.

Differences in molecular epidemiology of $C$. hominis between the developing and developed countries have been noticeable. In developing countries, the complexity of $C$. hominis infections in humans is reflected by the occurrence of multiple subtype families and multiple subtypes within families Ia and Id. Thus, three to four different $C$. hominis subtype families have been reported in humans in India. ${ }^{27,28}$ Extensive C. hominis heterogeneity in developing countries is an indicator of intensive and stable cryptosporidiosis transmission in these areas. Four common C. hominis subtype families, Ia, $\mathrm{Ib}$, Id, and Ie, are usually seen in humans in developing countries. However, there are geographic differences in the distribution. For example, all the four common subtype families were seen in children and HIV seropositive adults in India. Within each subtype family, one subtype is frequently seen in certain areas but not in others. For example, there are only two common subtypes within the $C$. hominis subtype family i.e., IbA9G3 and IbA10G2. The former is commonly seen in Malawi, Kenya, and India, whereas the latter is commonly seen in South Africa, Botswana, Jamaica, and Peru. ${ }^{47,97}$ The high virulence of the Ib subtype family in immune-competent persons is also reflected in the number of outbreaks caused by the parasite. Almost half of the $C$. hominis outbreaks in the United States, especially the major ones, were caused by the Ib subtype family, particularly the IbA10G2 subtype. IbA10G2 is apparently a major C. hominis subtype responsible for cryptosporidiosis outbreaks in Europe. ${ }^{98}$

Genotypes and subtypes along with clinical association have been shown in - Tables 1, 2, and 3 .

\section{Multilocus Sequence Typing}

This technique further allows the detection of length polymorphisms and nucleotide substitutions due to use of microsatellite and minisatellite markers and the single nucleotide polymorphisms (SNP), respectively.

Various markers that have been used over the years for multilocus sequence typing (MLST) include $70 \mathrm{kDa}$ heat-shock protein (HSP70) in chromosome 2, T-rich fragment (designated Chrom3T) coding for a hypothetical protein-cgd630 in chromosome 3 , and the following genes in chromosome 6 that are $60 \mathrm{kDa}$ glycoprotein (GP60), $47 \mathrm{kDa}$ protein (CP47), serine repeat antigen (MSC6-7), mucin-like protein (Mucin1), 56 kDa trans-membrane protein (CP56), 47-kDa protein (CP47 microsatellite), a serine repeat antigen (MSC6-7 minisatellite), a hypothetical retinitis pigmentosa GTPase regulator (RPGR minisatellite), and a hydroxyproline-rich glycoprotein (DZHRGP minisatellite and microsatellite).$^{84}$ Of these, the most polymorphic is the glycoprotein gene GP60. At the GP60 locus, subtype nomenclature is based on the combination of the number of serine coding trinucleotide repeats TCA, TCG, or TCT present in the microsatellite region and the SNP in the rest of the sequence..$^{99}$ The 
Table 1 Worldwide distribution of Cryptosporidium genotypes and subtypes

\begin{tabular}{|c|c|c|c|c|c|}
\hline Country & Cryptosporidium spp. & Subgenotype & Subtypes & & Reference \\
\hline Ontario & $\begin{array}{l}\text { C. hominis }(40 \%) \\
\text { C. parvum }(50 \%) \\
\text { C. cervine Genotype (10\%) }\end{array}$ & la, Id, le, Ila, & $\begin{array}{l}\text { laA19R3, laA23R4, IdA19, } \\
\text { leA11G3T3 }\end{array}$ & $\begin{array}{l}\text { IlaA17G2R1 (2), IlaA16G3R1 } \\
\text { (1), IlaA15G2R2 (1) }\end{array}$ & $\begin{array}{l}\text { Trotz-Williams, } \\
2006^{100}\end{array}$ \\
\hline Jamaica & $\begin{array}{l}\text { C. hominis }(73.5 \%) \\
\text { C. parvum }(20 \%) \\
\text { C. canis }(2.9 \%) \\
\text { C. felis }(2.9 \%)\end{array}$ & Ib, le, Ilc & $\begin{array}{l}\text { IbA10G2 (22) } \\
\text { leA12G3T3 (3) }\end{array}$ & IIcA5G3d (7) & Gatei et al, $2008^{97}$ \\
\hline Mexico & $\begin{array}{l}\text { C. hominis }(83.3 \%) \\
\text { C. parvum }(16.7 \%)\end{array}$ & la, Ib, Id, le, Ila & $\begin{array}{l}\text { laA14R3(2), laA15R3 (3), } \\
\text { lbA10G2 (1), IdA17 (1), } \\
\text { leA11G3T3 (3) }\end{array}$ & IlaA15G2R1(1) IlaA16G1R1(1) & $\begin{array}{l}\text { Valenzuela et al, } \\
2014^{101}\end{array}$ \\
\hline Portugal & $\begin{array}{l}\text { C. hominis }(35.7 \%) \\
\text { C. parvum }(64.3 \%)\end{array}$ & $\begin{array}{l}\text { la, Ib Id, le, If } \\
\text { lla, Ilb, Ilc, Ild }\end{array}$ & $\begin{array}{l}\text { laA19R3(1), IbA10G2(10) } \\
\text { IdA15(1), leA11G3T3(2) } \\
\text { IfA14G1(1) }\end{array}$ & $\begin{array}{l}\text { IlaA15G2R1 (9), IlbA14(1) } \\
\text { IlcA5G3a (1), IlcA5G3b(6) } \\
\text { IIdA17G1(2), IIdA19G1 (3) } \\
\text { IIdA21G1(2), IIdA22G1(1) }\end{array}$ & Alves et al, $2006^{102}$ \\
\hline Brazil & $\begin{array}{l}\text { C. hominis }(63 \%) \\
\text { C. parvum }(14.8 \%) \\
\text { C. felis }(18.5 \%) \\
\text { C. canis }(3.7 \%)\end{array}$ & & & & Lucca et al, $2009^{103}$ \\
\hline Brazil & $\begin{array}{l}\text { C. hominis }(57.1 \%) \\
\text { C. parvum }(14.2 \%) \\
\text { C. meleagridis }(14.2 \%)\end{array}$ & & & & Bushen et al, $2007^{104}$ \\
\hline Peru & $\begin{array}{l}\text { C. hominis }(73 \%) \\
\text { C. parvum }(11.3 \%) \\
\text { C. meleagridis }(8.8 \%) \\
\text { C. canis/C. felis }(6.2 \%) \\
\text { C. suis }(0.5 \%)\end{array}$ & la, Ib, Id, Ilc & $\begin{array}{l}\text { laA12R3 (1), laA12R4 (5) } \\
\text { laA12R5 (3), laA13R2 (1) } \\
\text { laA13R6 (1), laA13R7 (9) } \\
\text { laA13R8 (12), IaA14R7 (2) } \\
\text { laA17R6 (1), IbA10G2 (35) } \\
\text { lbA13G3 (4), IdA10 (25) } \\
\text { IdA12 (2), IdA15G1 (1) } \\
\text { IdA20 (12), leA11G3T3 (13) }\end{array}$ & $\begin{array}{l}\text { IlcA5G3a (16), IlcA5G3b (4) } \\
\text { IIcA5G3c (2) }\end{array}$ & Cama et al, $2007^{17}$ \\
\hline Peru & $\begin{array}{l}\text { C. hominis }(70 \%) \\
\text { C. parvum }(13.3 \%) \\
\text { C. meleagridis }(7.8 \%) \\
\text { C. canis }(1.5 \%) \\
\text { C. felis }(4.7 \%) \\
\text { C. hominis \& C. parvum } \\
(1.5 \%) \\
\text { C. canis \& C. meleagridis } \\
(0.7 \%)\end{array}$ & & $\begin{array}{l}\text { laA11R4 (3), laA12R4 (7) } \\
\text { laA13R4 (1), laA13R7 (1) } \\
\text { laA14R6 (5), laA15R3 (3) } \\
\text { IbA10G2 (23), IdA10 (9) } \\
\text { IdA15 (1), IdA20 (2) } \\
\text { leA11G3T3 (19) }\end{array}$ & $\begin{array}{l}\text { IlcA5G3a (12), IlcA5G3b (1) } \\
\text { IIcA5G3c (1) }\end{array}$ & Cama et al, $2008^{47}$ \\
\hline Australia & $\begin{array}{l}\text { C. hominis }(53.6 \%) \\
\text { C. parvum }(46.3 \%)\end{array}$ & Ib, Id, Ila & $\begin{array}{l}\text { IbA10G2, IbA9G2 } \\
\text { IdA26, IdA15 }\end{array}$ & $\begin{array}{l}\text { IlaA18G3R1, IlaA17G3R1 } \\
\text { IlaA20G5R1, IlaA20G3R1 } \\
\text { IlaA17G4R1, Ila16G3R1 }\end{array}$ & Waldron $2009^{105}$ \\
\hline Australia & & Ib, Ila & $\begin{array}{l}\text { IbA10G2R2, IbA15G1R2 } \\
\text { Ib2A18G1R4 }\end{array}$ & $\begin{array}{l}\text { IlaA18G3R1, IlaA20G3R1 } \\
\text { IlaA23G3R1, IlaA23G3R1 } \\
\text { IlaA5G3R2 }\end{array}$ & Jex et al, $2007^{106}$ \\
\hline Australia & $\begin{array}{l}\text { C. hominis }(42.8 \%) \\
\text { C. parvum }(57.2 \%)\end{array}$ & Ib, Ila & IbA10G2, IbA15G1 & $\begin{array}{l}\text { IlaA17G2R1, IlaA18G3R1 } \\
\text { IlaA19G3R1, IlaA20G3R1 }\end{array}$ & $\mathrm{Ng}$ et al, $2008^{107}$ \\
\hline Australia & $\begin{array}{l}\text { C. hominis }(78.6 \%) \\
\text { C. parvum }(19.8 \%) \\
\text { C. meleagridis }(1.6 \%)\end{array}$ & $\begin{array}{l}\text { Ib, Id, le, If, Ig } \\
\text { lla, Ild }\end{array}$ & & & $\mathrm{Ng}$ et al, $2010^{108}$ \\
\hline Australia & $\begin{array}{l}\text { C. hominis }(82 \%) \\
\text { C. parvum }(18 \%)\end{array}$ & $\begin{array}{l}\text { la, Ib, Id, If, } \\
\text { Ila, Ilc }\end{array}$ & $\begin{array}{l}\text { IaA23 (1), IbA5G2T3 (1) } \\
\text { IbA9G2 (1), IbA9G2T1 (1) } \\
\text { IbA10G2 (21), IdA15G1 (9) } \\
\text { IdA16 (1), IdA25 (3) } \\
\text { IfA11G1T1 (1), IfA12G1 (2) }\end{array}$ & $\begin{array}{l}\text { IlaA15G2R1 (2),IlaA17G2R1 (1) } \\
\text { IlaA18G3R1 (3), IlaA19G2R1(1) } \\
\text { IlaA19G3R1 (1), IlcA5G3a (1) }\end{array}$ & O Brien et al, $2008^{109}$ \\
\hline UK & C. hominis & la, lb & $\begin{array}{l}\text { IbA10G2(10), laA12R3(1) } \\
\text { laA22R2(1) laA30R3(1) } \\
\text { laA25R3 (1), IgA24 (2) }\end{array}$ & & Chalmers et al, $2008^{98}$ \\
\hline
\end{tabular}


Table 1 (Continued)

\begin{tabular}{|c|c|c|c|c|c|}
\hline Country & Cryptosporidium spp. & Subgenotype & Subtypes & & Reference \\
\hline Europe & $\begin{array}{l}\text { C. hominis }(75 \%) \\
\text { C. parvum (25\%) }\end{array}$ & & IbA10G2 (5), IdA15G1 (1) & IlaA18G3R1 (1), IIdA22G1 (1) & O Brien et al, $2008^{109}$ \\
\hline France & $\begin{array}{l}\text { C. hominis }(31.6 \%) \\
\text { C. parvum }(42 \%) \\
\text { C. meleagridis }(5.2 \%) \\
\text { C. felis }(10.5 \%) \\
\text { C. muris }(1.7 \%)\end{array}$ & & & & Guyot et al, $2001^{110}$ \\
\hline Ireland & $\begin{array}{l}\text { C. hominis (24\%) } \\
\text { C. parvum }\end{array}$ & & IbA10G2(25) & $\begin{array}{l}\text { IlaA18G3R1(48), } \\
\text { IlaA18G3R1(9) } \\
\text { IlaA20G3R1(7), IlaA15G2R1(6) } \\
\text { IlaA19G3R1(2), IlaA17G1R1(1) } \\
\text { IlaA10G2R1(1), IlaA14G2R1(1) } \\
\text { IlaA16G3R1(1), IlaA17G2R1(1) } \\
\text { IlaA20G5R1(1), IlaA21G3R1(1) } \\
\text { IldA26G1 (1) }\end{array}$ & Zintl et al, $2008^{111}$ \\
\hline $\begin{array}{l}\text { South } \\
\text { Africa }\end{array}$ & C. parvum (22) & Ic, Id, Ib, le, la & & & Leav et al, $2002^{112}$ \\
\hline Ethiopia & $\begin{array}{l}\text { C. hominis }(18 \%) \\
\text { C. parvum }(65.7 \%) \\
\text { C. viatorum }(7.1 \%) \\
\text { C. canis }(1.4 \%) \\
\text { C. felis }(3.5 \%) \\
\text { C. meleagridis }(2 \%) \\
\text { C. xioai }(1.4 \%)\end{array}$ & $\begin{array}{l}\text { Ib, Id, le, Ila, } \\
\text { Ilb, Ilc, Ild, Ile, } \\
\text { If like }\end{array}$ & $\begin{array}{l}\text { IbA10G2(1), IdA20(10), } \\
\text { IdA24(1), IdA26(2), } \\
\text { IeA11C3T3(5) }\end{array}$ & $\begin{array}{l}\text { IlaA13G2R1 (1), IlaA14G2R1 } \\
\text { (1), IlaA15G2R1(60), } \\
\text { IlaA16G2R1 (1), } \\
\text { IlaA16G2R1(4), IlaA17G2R1(2), } \\
\text { IlaA18G2R1 (1), IlaA19G1R1 (1), } \\
\text { IlbA12(1), IlcA5G3(2), } \\
\text { IIdA17G1(1), IIdA19G1(1), } \\
\text { IldA22G1(2), IIdA24G1(1) }\end{array}$ & Adamu et al, 2014 113 \\
\hline Kenya & $\begin{array}{l}\text { C. hominis }(68.2 \%) \\
\text { C. parvum }(18.2 \%) \\
\text { C. meleagridis }(13.6 \%)\end{array}$ & & & & $\begin{array}{l}\text { Nyamwange et al, } \\
2012^{116}\end{array}$ \\
\hline Nigeria & $\begin{array}{l}\text { C. hominis }(44.2 \%) \\
\text { C. parvum }(32.5 \%) \\
\text { C. hominis \& C. parvum } \\
\text { (5.2\%) } \\
\text { C. meleagridis }(6.5 \%) \\
\text { C. rabbit genotype }(6.5 \%) \\
\text { C. cervine genotype }(3.9 \%) \\
\text { C. canis }(1.3 \%)\end{array}$ & $\begin{array}{l}\text { la, Ib, Id, le, Ih, } \\
\text { Ila, Ilc, Ili, IIm }\end{array}$ & $\begin{array}{l}\text { laA18R2 (3), IaA22R2 (1), } \\
\text { laA24R2 (2), IaA25R2 (2), } \\
\text { laA28R2(1), laA21R1(1) } \\
\text { IbA10G2(3),IbA13G3(7) } \\
\text { IdA11(2), IdA17(2) } \\
\text { leA11G3T3(3) } \\
\text { IhA14G1(1) }\end{array}$ & $\begin{array}{l}\text { IlaA15G2R1(1), IlaA16G1R1(1) } \\
\text { IlcA5G3a (9), IlcA5G3b(8) } \\
\text { IliA11(2), IImA14G1(2) }\end{array}$ & Molloy et al, $2011^{114}$ \\
\hline Jordan & $\begin{array}{l}\text { C. parvum (22) } \\
\text { C. hominis (20) } \\
\text { C. meleagridis (1) } \\
\text { C. canis (1) }\end{array}$ & Ibld,Ila IIb, Ilc & $\begin{array}{l}\text { IbA6G3(3), IbA9G3(3) } \\
\text { IbA10G2 (1), IbA20G2(1) } \\
\text { Id IdA21 (2), IdA24 (5) }\end{array}$ & $\begin{array}{l}\text { IlaA15G1R1(2), IlaA20G3R1(1) } \\
\text { IlcA5G3a (2), IIdA14G1 (1) } \\
\text { IIdA20G1 (5), IIdA24G1 (1) } \\
\text { IIdA29G1 (1) }\end{array}$ & Hijjawi et al, $2010^{29}$ \\
\hline Yemen & $\begin{array}{l}\text { C. hominis }(3 \%) \\
\text { C. parvum }(97 \%)\end{array}$ & le, Ila & leA11G3T3 (1) & IlaA15G2R1(7) & Alyousefi et al, $2013^{115}$ \\
\hline Japan & $\begin{array}{l}\text { C. hominis }(75 \%) \\
\text { C. parvum }(25 \%)\end{array}$ & lela, Ilc, Ib & & & Abe et al, $2006^{92}$ \\
\hline Kuwait & $\begin{array}{l}\text { C. hominis }(26.5 \%) \\
\text { C. parvum }(73.5 \%)\end{array}$ & $\begin{array}{l}\text { la, Id, le, Ila, } \\
\text { Ilc, Ild }\end{array}$ & & & Iqbal et al, $2011^{117}$ \\
\hline India & $\begin{array}{l}\text { C. hominis (49) } \\
\text { C. meleagridis (2) } \\
\text { C. felis (1) }\end{array}$ & la,lb,le,Id & $\begin{array}{l}\text { IbA9G3 (17), leA11G3T3 (5), } \\
\text { laA12G1R3 (1), laA19R3 (4), } \\
\text { laA21R3 (1), laA22R3 (1), } \\
\text { IdA15G1 (13), IdA16 (4) }\end{array}$ & & Gatei et al, $2007^{84}$ \\
\hline India & $\begin{array}{l}\text { C. hominis }(81 \%) \\
\text { C. parvum }(12 \%) \\
\text { C. felis }(5.2 \%) \\
\text { C. parvum (mouse } \\
\text { genotype }\end{array}$ & la, Ib, Ic, Id, le & & & $\begin{array}{l}\text { Rao Ajjampur et al, } \\
2007^{118}\end{array}$ \\
\hline India & $\begin{array}{l}\text { C. hominis }(88.1 \%) \\
\text { C. parvum }(10.5 \%) \\
\text { C. meleagridis }(1 \%)\end{array}$ & $\begin{array}{l}\text { la, Ib, Id, le, If, } \\
\text { Ilc, Ild, IIm, Iln }\end{array}$ & $\begin{array}{l}\text { laA18, laA19, leA11G3T3, } \\
\text { IfA13G1 }\end{array}$ & $\begin{array}{l}\text { IlcA5G3, IIdA15G1, IImA7G1, } \\
\text { IInA8 }\end{array}$ & Ajjampuret al, $2010^{95}$ \\
\hline
\end{tabular}


Table 1 (Continued)

\begin{tabular}{|c|c|c|c|c|c|}
\hline Country & Cryptosporidium spp. & Subgenotype & Subtypes & & Reference \\
\hline India & $\begin{array}{l}\text { C. hominis }(67 \%) \\
\text { C. parvum }(22.4 \%) \\
\text { C. meleagridis }(1.7 \%)\end{array}$ & $\begin{array}{l}\text { la,lb, Id, le, Ilc, } \\
\text { Ild, lle }\end{array}$ & $\begin{array}{l}\text { laA18R3, laA19R3, laA21R3, } \\
\text { laA26R3, laA27R3, } \\
\text { laA29G1T3R3b IbA9G3 } \\
\text { IdA14G1, IdA15G11, } \\
\text { IdA16G1, leA11G3T21, } \\
\text { leA11G3T3, IfA13G1 }\end{array}$ & $\begin{array}{l}\text { IlcA5G3a } \\
\text { IldA14G1, IIdA15G1 } \\
\text { IleA7G1b }\end{array}$ & Sharma et al, $2013^{44}$ \\
\hline India & $\begin{array}{l}\text { C. hominis } \mathbf{6 4 \%}(54 / 84) \\
\text { C. parvum } \mathbf{2 7 \%}(23 / 84)\end{array}$ & $\begin{array}{l}\text { le, la, Id } \\
\text { Ib If } \\
\text { llc } \\
\text { II d } \\
\text { Ila } \\
\text { IId } \\
\text { Ilb }\end{array}$ & $\begin{array}{l}\text { IdA15G1 }(41.7 \%, 10 / 24), \\
\text { IbA9G3 }(16.7 \%, 4 / 24), \\
\text { leA11G3T3 }(4.2 \%, 1 / 24), \\
\text { IfA14G1 }(8.3 \%, 2 / 24), \\
\text { IbA10G2 }(4.2 \%, 1 / 24) \text {, } \\
\text { IdA17G1 }(4.2 \%, 1 / 24) \text { and } \\
\text { laA19R3 }(4.2 \%, 1 / 24)\end{array}$ & & Yadav et al, $2016^{119}$ \\
\hline
\end{tabular}

Table 2 Subtype families of Cryptosporidium spp. reported from Indian subcontinent

\begin{tabular}{|c|c|c|}
\hline $\begin{array}{l}\text { C. hominis (98\%) } \\
\text { C. felis }(2 \%)\end{array}$ & la, Ib, le, Id & Gatei et al, $2007^{84}$ \\
\hline $\begin{array}{l}\text { C. hominis (64\%) } \\
\text { C. parvum (18\%) } \\
\text { C. parvum (mouse) (2\%) } \\
\text { C. melegridis (2\%) } \\
\text { C. muris }(2 \%)\end{array}$ & la, Ib, Ic, Id, Ig, If, Ila, IIb, IIc & Muthusamy et al, $2006^{27}$ \\
\hline $\begin{array}{l}\text { C. hominis }(87.5 \%) \\
\text { C. parvum }(10 \%) \\
\text { C. felis }(2.5 \%)\end{array}$ & & Das et al, $2006^{120}$ \\
\hline $\begin{array}{l}\text { C. hominis }(81 \%) \\
\text { C. parvum }(12 \%) \\
\text { C. felis }(5.2 \%) \\
\text { C. parvum (mouse genotype) }\end{array}$ & la, Ib, Ic, Id, le & Rao Ajjampur et al, $2007^{118}$ \\
\hline $\begin{array}{l}\text { C. hominis }(88.1 \%) \\
\text { C. parvum }(10.5 \%) \\
\text { C. meleagridis }(1 \%)\end{array}$ & la, Ib, Id, le, If, Ilc, Ild, IIm, IIn & Ajjampur et al, $2010^{95}$ \\
\hline $\begin{array}{l}\text { C. hominis }(67 \%) \\
\text { C. parvum }(22.4 \%) \\
\text { C. meleagridis }(1.7 \%) \\
\end{array}$ & la,Ib, Id, le, Ilc, Ild, Ile & Sharma et al, $2013^{44}$ \\
\hline
\end{tabular}

Table 3 Subtype family association with clinical outcome of Cryptosporidiosis

\begin{tabular}{|c|c|c|c|c|c|c|c|}
\hline & $\begin{array}{l}\text { Cama et al, } \\
2007^{17} \\
\text { (HIV adults) }\end{array}$ & $\begin{array}{l}\text { Cama et al, } \\
2008^{47} \\
\text { (children) }\end{array}$ & $\begin{array}{l}\text { Ajjampur et al, } \\
2010^{95} \\
\text { (children) }\end{array}$ & $\begin{array}{l}\mathrm{Ng} \text { et al, } \\
2010^{107}\end{array}$ & $\begin{array}{l}\text { Chierico et al, } \\
2011^{121} \\
\text { (HIV adults) }\end{array}$ & $\begin{array}{l}\text { lqbal et al, } \\
2011^{117} \\
\text { (children) }\end{array}$ & $\begin{array}{l}\text { Adamu et al, } \\
2014^{113} \\
\text { (HIV adults) }\end{array}$ \\
\hline la & No association & Diarrhea & No association & & $\begin{array}{l}\text { No association } \\
\text { with wasting }\end{array}$ & & \\
\hline Ib & $\begin{array}{l}\text { Marginally } \\
\text { with diarrhea, } \\
\text { vomiting }\end{array}$ & $\begin{array}{l}\text { Nausea, } \\
\text { vomiting } \\
\text { malaise, diarrhea }\end{array}$ & No association & & & & \\
\hline Id & $\begin{array}{l}\text { Chronic } \\
\text { diarrhea }\end{array}$ & Diarrhea & $\begin{array}{l}\text { Shorter } \\
\text { duration of } \\
\text { diarrhea }\end{array}$ & Abdominal pain & & $\begin{array}{l}\text { Fever, } \\
\text { dehydration, } \\
\text { severe diarrhea }\end{array}$ & \\
\hline IIC & & Vomiting & & & $\begin{array}{l}\text { Wasting } \\
\text { syndrome }\end{array}$ & & \\
\hline Ila & & & & & & & Diarrhea \\
\hline
\end{tabular}

Abbreviation: HIV, human immunodeficiency virus.

diversity at MLST is more pronounced at $C$. parvum loci compared with $C$. hominis. The high genetic diversity of CP47 and MSC6-7 has also been reported and CP47 locus has been suggested as an alternative for the typing $C$. hominis and $C$. parvum. CP47 has a high resolution for both length polymorphism and MLST-based typing that distinguishes $C$. hominis and C. parvum by size. ${ }^{84}$

\section{Clinical Association of Cryptosporidium Subtypes}

Number of studies in last over a half decade emphasized on the significant role of subtypes in the clinical manifestation of the cryptosporidiosis (- Table 3 ). A recent study reported that the Ib subtype family appeared to be much more virulent than other subtype families and was significantly associated with diarrhea, nausea, vomiting, and 
general malaise. ${ }^{96}$ Worldwide, IbA9G3 and IbA10G2 are the two common subtypes reported within the Ib subtype family. Subtype IbA10G2 has a global distribution. IbA9G3 has been commonly reported in humans in Malawi, Kenya, India, and Australia, whereas IbA10G2 in South Africa, Botswana, Jamaica, Peru, United States, Canada, Australia, and European countries. ${ }^{97,98}$ It has been reported that IbA10G2 is responsible for more than half of the water-borne outbreaks of gastroenteritis in the United States, United Kingdom, Canada, and France..$^{96}$ Variations in the pattern of clinical manifestations were observed among C. hominis subtype families. Infections with subtype family Ib were associated with nausea, vomiting, general malaise, and diarrhea. Infection with other subtype families (Ia, Id, and Ie) were generally associated with diarrhea symptom only.

In a study on pediatric cryptosporidiosis from Kolkata, IbA9G3, IeA11G3T3, IaA12G1R3, IaA19R3, IaA21R3, IaA22R3, IdA15G1, and IdA16 subtypes were identified at gp60 locus. ${ }^{84}$ However, association of these subtypes with the clinical manifestations has not been reported in this study. The subtypes identified from Delhi were IdA15G1 (41.7\%, 10/24), IbA9G3 (16.7\%, 4/24), IeA11G3T3 (4.2\%, 1/24), IfA14G1 (8.3\%, 2/24), IbA10G2 (4.2\%, 1/24), IdA17G1 (4.2\%, 1/24), and laA19R3 (4.2\%, 1/24). Four $(16.7 \%)$ patients, however, had mixed infections with IdA15G1 and IeA11G3T3 subtypes. ${ }^{85}$

\section{Conclusion and Future Perspective}

The occurrence and distribution of Cryptosporidium species among human hosts are similar to that described elsewhere including report of unique variants. Conditions contributing to observed cryptosporidiosis prevalence indicate contact and exposure variability of both human and animal populations. Molecular epidemiological studies on cryptosporidiosis have significantly broadened the understanding of transmission dynamics and information about distribution of circulating genotype(s) and subtype(s). Distribution of different subtypes and association of particular subtypes with the some of the outbreaks and diseased conditions clearly indicate emergence of virulent ones.

\section{Conflict of Interest}

None declared.

\section{References}

1 Tyzzer EE. A sporozoan found in the peptic glands of the common mouse. Proc Soc Exp Biol Med 1907;5:12-13

2 Meisel JL, Perera DR, Meligro C, Rubin CE. Overwhelming watery diarrhea associated with a cryptosporidium in an immunosuppressed patient. Gastroenterology 1976;70(6):1156-1160

3 Nime FA, Burek JD, Page DL, Holscher MA, Yardley JH. Acute enterocolitis in a human being infected with the protozoan Cryptosporidium. Gastroenterology 1976;70(4):592-598

4 Parasites - Cryptosporidium (also known as "Crypto"). Available at: https://www.cdc.gov/parasites/crypto/illness.html

5 Gentile G, Venditti M, Micozzi A, et al. Cryptosporidiosis in patients with hematologic malignancies. Rev Infect Dis 1991;13(5):842-846
6 Blanshard C, Jackson AM, Shanson DC, Francis N, Gazzard BG. Cryptosporidiosis in HIV-seropositive patients. Q J Med 1992;85(307-308):813-823

7 Farthing MJ. Clinical aspects of human cryptosporidiosis. Contrib Microbiol 2000;6:50-74

8 Tumwine JK, Kekitiinwa A, Nabukeera N, et al. Cryptosporidium parvum in children with diarrhea in Mulago Hospital, Kampala, Uganda. Am J Trop Med Hyg 2003;68(6):710-715

9 Pandak N, Zeljka K, Cvitkovic A. A family outbreak of cryptosporidiosis: Probable nosocomial infection and person-to-person transmission. Wien Klin Wochenschr2006;118(15-16):485-487

10 Xiao L, Feng Y. Zoonotic cryptosporidiosis. FEMS Immunol Med Microbiol 2008;52(3):309-323

11 Ryan U, Fayer R, Xiao L. Cryptosporidium species in humans and animals: current understanding and research needs. Parasitology 2014;141(13):1667-1685

12 Robertson LJ, Gjerde BK. Cryptosporidium oocysts: challenging adversaries? Trends Parasitol 2007;23(8):344-347

13 Pereira SJ, Ramirez NE, Xiao L, Ward LA. Pathogenesis of human and bovine Cryptosporidium parvum in gnotobiotic pigs. J Infect Dis 2002;186(5):715-718

14 Okhuysen PC, Chappell CL, Crabb JH, Sterling CR, DuPont HL. Virulence of three distinct Cryptosporidium parvum isolates for healthy adults. J Infect Dis 1999;180(4):1275-1281

15 O'Donoghue PJ. Cryptosporidium and cryptosporidiosis in man and animals. Int J Parasitol 1995;25(2):139-195

16 Widmer G, Carmena D, Kváč M, etal.Update on Cryptosporidium spp.: highlights from the Seventh International Giardia and Cryptosporidium Conference. Parasite 2020;27:14

17 Cama VA, Ross JM, Crawford S, et al. Differences in clinical manifestations among Cryptosporidium species and subtypes in HIV-infected persons. J Infect Dis 2007;196(5):684-691

18 Ajjampur SS, Sarkar R, Sankaran P, et al. Symptomatic and asymptomatic Cryptosporidium infections in children in a semi-urban slum community in southern India. Am J Trop Med Hyg 2010;83(5):1110-1115

19 Coutinho BP, Oriá RB, Vieira CM, et al. Cryptosporidium infection causes undernutrition and, conversely, weanling undernutrition intensifies infection. J Parasitol 2008;94(6):1225-1232

20 Chalmers RM, Davies AP. Minireview: clinical cryptosporidiosis. Exp Parasitol 2010;124(1):138-146

21 Clark DP. New insights into human cryptosporidiosis. Clin Microbiol Rev 1999;12(4):554-563

22 Mathan MM, Venkatesan S, George R, Mathew M, Mathan VI. Cryptosporidium and diarrhoea in southern Indian children. Lancet 1985;2(8465):1172-1175

23 Fayer R. Cryptosporidium: a water-borne zoonotic parasite. Vet Parasitol 2004;126(1-2):37-56

24 Areeshi M, Dove W, Papaventsis D, et al. Cryptosporidium species causing acute diarrhoea in children in Antananarivo, Madagascar. Ann Trop Med Parasitol 2008;102(4):309-315

25 Yoder JS, Wallace RM, Collier SA, Beach MJ, Hlavsa MC; Centers for Disease Control and Prevention (CDC). Cryptosporidiosis surveillance-United States, 2009-2010. MMWR Surveill Summ 2012;61(5):1-12

26 Health Protection Agency. Available at: www.hpa.org.uk.

27 Muthusamy D, Rao SS, Ramani S, et al. Multilocus genotyping of Cryptosporidium sp. isolates from human immunodeficiency virus-infected individuals in South India. J Clin Microbiol 2006;44(2):632-634

28 Rao Ajjampur SS, Asirvatham JR, Muthusamy D, et al. Clinical features \& risk factors associated with cryptosporidiosis in HIV infected adults in India. Indian J Med Res 2007; 126(6):553-557

29 Hijjawi N, Ng J, Yang R, Atoum MF, Ryan U. Identification of rare and novel Cryptosporidium GP60 subtypes in human isolates from Jordan. Exp Parasitol 2010;125(2):161-164 
30 Meinhardt PL, Casemore DP, Miller KB. Epidemiologic aspects of human cryptosporidiosis and the role of waterborne transmission. Epidemiol Rev 1996;18(2):118-136

31 Jagai JS, Castronovo DA, Monchak J, Naumova EN. Seasonality of cryptosporidiosis: a meta-analysis approach. Environ Res 2009;109(4):465-478

32 Nath G, Choudhury A, Shukla BN, Singh TB, Reddy DCS. Significance of Cryptosporidium in acute diarrhoea in NorthEastern India. J Med Microbiol 1999;48(6):523-526

33 Ajjampur SS, Sankaran P, Kang G. Cryptosporidium species in HIV-infected individuals in India: an overview. Natl Med J India 2008;21(4):178-184

34 Kulkarni SV, Kairon R, Sane SS, et al. Opportunistic parasitic infections in HIV/AIDS patients presenting with diarrhoea by the level of immunesuppression. Indian J Med Res 2009;130(1):63-66

35 Vignesh R, Balakrishnan P, Shankar EM, et al. High proportion of isosporiasis among HIV-infected patients with diarrhea in southern India. Am J Trop Med Hyg 2007;77(5):823-824

36 Masarat S, Ahmad F, Chisti M, Hamid S, Sofi BA. Prevalence of Cryptosporidium species among HIV positive asymptomatic and symptomatic immigrant population in Kashmir, India. Iran J Microbiol 2012;4(1):35-39

37 Patel SD, Kinariwala DM, Javadekar TB. Clinico-microbiological study of opportunistic infection in HIV seropositive patients. Indian J Sex Transm Dis AIDS 2011;32(2):90-93

38 Gupta S, Narang S, Nunavath V, Singh S. Chronic diarrhoea in HIV patients: prevalence of coccidian parasites. Indian J Med Microbiol 2008;26(2):172-175

39 Gautam H, Bhalla P, Saini S, et al. Epidemiology of opportunistic infections and its correlation with CD4 T-lymphocyte counts and plasma viral load among HIV-positive patients at a tertiary care hospital in India. J Int Assoc Physicians AIDS Care (Chic) 2009;8(6):333-337

40 Ramakrishnan K, Shenbagarathai R, Uma A, Kavitha K, Rajendran R, Thirumalaikolundusubramanian P. Prevalence of intestinal parasitic infestation in HIV/AIDS patients with diarrhea in Madurai City, South India. Jpn J Infect Dis 2007;60(4):209-210

41 Deorukhkar S, Katiyar R, Saini S, et al. The prevalence of intestinal parasitic infections in HIV infected patients in a rural tertiary care hospital of Western Maharashtra. (A 5 year study) J Clin Diagn Res 2011;5:210-212

42 Tuli L, Gulati AK, Sundar S, Mohapatra TM. Correlation between CD4 counts of HIV patients and enteric protozoan in different seasons - an experience of a tertiary care hospital in Varanasi (India) BMC Gastroenterol 2008;8:36

43 Anand L, Brajachand NG, Dhanachand CH. Cryptosporidiosis in HIV infection. J Commun Dis 1996;28(4):241-244

44 Sharma P, Sharma A, Sehgal R, Malla N, Khurana S. Genetic diversity of Cryptosporidium isolates from patients in North India. Int J Infect Dis 2013;17(8):e601-e605

45 Khalil S, Mirdha BR, Paul J, Panda A, Singh Y. Molecular detection and identification of Cryptosporidium viatorum in a human immunodeficiency virus-seropositive patient. J Glob Infect Dis 2018;10(1):28-29

46 Raccurt CP, Brasseur P, Verdier RI, et al. [Human cryptosporidiosis and Cryptosporidium spp. in Haiti]. Trop Med Int Health 2006;11(6):929-934

47 Cama VA, Bern C, Roberts J, et al. Cryptosporidium species and subtypes and clinical manifestations in children, Peru. Emerg Infect Dis 2008;14(10):1567-1574

48 Swathirajan CR, Vignesh R, Pradeep A, Solomon SS, Solomon S, Balakrishnan P. Occurrence of enteric parasitic infections among HIV-infected individuals and its relation to $\mathrm{CD} 4 \mathrm{~T}$-cell counts with a special emphasis on coccidian parasites at a tertiary care centre in South India. Indian J Med Microbiol 2017;35(1):37-40

49 Uppal B, Singh O, Chadha S, Jha AK. A comparison of nested PCR assay with conventional techniques for diagnosis of intestinal cryptosporidiosis in AIDS cases from northern India. J Parasitol Res 2014;2014:706105

50 Chen XM, LaRusso NF. Cryptosporidiosis and the pathogenesis of AIDS-cholangiopathy. Semin Liver Dis 2002;22(3):277-289

51 Babiker A, Darbyshire J, Pezzotti P, et al; CASCADE Collaboration. Changes over calendar time in the risk of specific first AIDSdefining events following HIV seroconversion, adjusting for competing risks. Int J Epidemiol 2002;31(5):951-958

52 Soave R, Ma P. Cryptosporidiosis. Traveler's diarrhea in two families. Arch Intern Med 1985;145(1):70-72

53 Das P, Pal S, Dutta D, Bhattacharya MK, Pal SC. Cryptosporidiosis in Bengali children with acute diarrhoea. Trans R Soc Trop Med Hyg 1987;81(2):241

54 Palit A, Sur D, Mitra Dhar K, Saha MR. Asymptomatic cryptosporiosis in a periurban slum setting in Kolkata, India-a pilot study. Jpn J Infect Dis 2005;58:110-111

55 Mall AN, Sehagal R, Ganguly NK, Mahajan RC. Cryptosporidiosis in children in Chandigarh. Ind. J Med Res 1987;86:722-725

56 Sen D, Sha MR, Nair GB, et al. Etiological spectrum of acute diarrhoea in hospitalised patients in Calcutta. Ind J Med Res;1985;286-291

57 Pherwani AV, Bhave SY, Bijm AM, Desai AG. Prevalence of cryptosporidium in children with acute diarrhea. Indian J Pediatr 1989;56(1):133-135

58 Dwivedi KK, Prasad G, Saini S, Mahajan S, Lal S, Baveja UK. Enteric opportunistic parasites among HIV infected individuals: associated risk factors and immune status. Jpn J Infect Dis 2007;60(2-3):76-81

59 Sarkar R, Ajjampur SS, Prabakaran AD, et al. Cryptosporidiosis among children in an endemic semiurban community in southern India: does a protected drinking water source decrease infection? Clin Infect Dis 2013;57(3):398-406

60 Bera P, Das S, Saha R, Ramachandran VG, Shah D. Cryptosporidium in children with diarrhea: a hospital-based Study. Indian Pediatr 2014;51(11):906-908

61 Platts-Mills JA, Babji S, Bodhidatta L, et al; MAL-ED Network Investigators. Pathogen-specific burdens of community diarrhoea in developing countries: a multisite birth cohort study (MAL-ED) Lancet Glob Health 2015;3(9):e564-e575

62 Al-Brikan FA, Salem HS, Beeching N, Hilal N. Multilocus genetic analysis of Cryptosporidium isolates from Saudi Arabia. J Egypt Soc Parasitol 2008;38(2):645-658

63 Xiao L, Ryan UM. Cryptosporidiosis: an update in molecular epidemiology. Curr Opin Infect Dis 2004;17(5):483-490

64 Maikai BV, Umoh JU, Lawal IA, Kudi AC, Ejembi CL, Xiao L. Molecular characterizations of Cryptosporidium, Giardia, and Enterocytozoon in humans in Kaduna State, Nigeria. Exp Parasitol 2012;131(4):452-456

65 Opintan JA, Newman MJ, Ayeh-Kumi PF, et al. Pediatric diarrhea in southern Ghana: etiology and association with intestinal inflammation and malnutrition. Am J Trop Med Hyg 2010;83(4):936-943

66 Lorntz B, Soares AM, Moore SR, et al. Early childhood diarrhea predicts impaired school performance. Pediatr Infect Dis J 2006;25(6):513-520

67 Mor SM, Tzipori S. Cryptosporidiosis in children in SubSaharan Africa: a lingering challenge. Clin Infect Dis 2008; 47(7):915-921

68 Behera B, Mirdha BR, Makharia GK, Bhatnagar S, Dattagupta S, Samantaray JC. Parasites in patients with malabsorption syndrome: a clinical study in children and adults. Dig Dis Sci 2008;53(3):672-679 
69 Kang G, Srivastava A, Pulimood AB, Dennison D, Chandy M. Etiology of diarrhea in patients undergoing allogeneic bone marrow transplantation in South India. Transplantation 2002;73(8):1247-1251

70 Weisburger WR, Hutcheon DF, Yardley JH, Roche JC, Hillis WD, Charache P. Cryptosporidiosis in an immunosuppressed renal-transplant recipient with IgA deficiency. Am J Clin Pathol 1979;72(3):473-478

71 Minz M, Udgiri NK, Heer MK, Kashyap R, Malla N. Cryptosporidiasis in live related renal transplant recipients: a single center experience. Transplantation 2004;77(12):1916-1917

72 Bhadauria D, Goel A, Kaul A, et al. Cryptosporidium infection after renal transplantation in an endemic area. Transpl Infect Dis 2015;17(1):48-55

73 Yadav P, Khalil S, Mirdha BR. Molecular appraisal of intestinal parasitic infection in transplant recipients. Indian J Med Res 2016;144(2):258-263

74 Ghoshal U, Ranjan P, Dey A, Ghoshal UC. Intestinal cryptosporidiosis in renal transplant recipients: prevalence, species detection and comparative evaluation of SSU rRNA and Cryptosporidium oocyst wall protein genes. Indian J Med Microbiol 2018;36(2):247-250

75 Rudrapatna JS, Kumar V, Sridhar H. Intestinal parasitic infections in patients with malignancy. J Diarrhoeal Dis Res 1997;15(2):71-74

76 Sreedharan A, Jayshree RS, Sridhar H. Cryptosporidiosis among cancer patients: an observation. J Diarrhoeal Dis Res 1996;14(3):211-213

77 Zhang N, Yu X, Zhang H, et al. Prevalence and genotyping of Cryptosporidium parvum in gastrointestinal cancer patients. J Cancer 2020;11(11):3334-3339

78 Efstratiou A, Ongerth JE, Karanis P. Waterborne transmission of protozoan parasites: review of worldwide outbreaks - an update 2011-2016. Water Res 2017;114:14-22

79 Ryan U, Hijjawi N, Xiao L. Foodborne cryptosporidiosis. Int J Parasitol 2018;48(1):1-12

80 Tali A, Addebbous A, Asmama S, Chabaa L, Zougaghi L. Respiratory cryptosporidiosis in two patients with HIV infection in a tertiary care hospital in Morocco. Ann Biol Clin (Paris) 2011;69(5):605-608

81 Kourda N, Blel A, Ben Jilani SB, Zermani R. [Gastric cryptosporidiosis revealing a small cell lung carcinoma (Tunisia)]. Bull Soc Pathol Exot 2008;101(1):22-23

82 Kumar H, Singh VB, Meena BL, Agrawal J, Beniwal S, Swami T. Pulmonary cryptosporidiosis in an immunocompetent host treated successfully with nitazoxanide. Lung India 2016;33(1):69-71

83 Shrikhande SN, Chande CA, Shegokar VR, Powar RM. Pulmonary cryptosporidiosis in HIV negative, immunocompromised host. Indian J Pathol Microbiol 2009;52(2):267-268

84 Gatei W, Das P, Dutta P, et al. Multilocus sequence typing and genetic structure of Cryptosporidium hominis from children in Kolkata, India. Infect Genet Evol 2007;7(2):197-205

85 Yadav P, Mirdha BR, Makharia GK, Chaudhry R. Multilocus sequence typing of Cryptosporidium hominis from northern India. Indian J Med Res 2017;145(1):102-111

86 Cacciò SM. Molecular epidemiology of human cryptosporidiosis. Parassitologia 2005;47(2):185-192

87 Alves M, Matos O, Antunes F. Multilocus PCR-RFLP analysis of Cryptosporidium isolates from HIV-infected patients from Portugal. Ann Trop Med Parasitol 2001;95(6):627-632

88 Cacciò S, Pinter E, Fantini R, Mezzaroma I, Pozio E. Human infection with Cryptosporidium felis: case report and literature review. Emerg Infect Dis 2002;8(1):85-86

89 Ong CS, Eisler DL, Alikhani A, et al. Novel cryptosporidium genotypes in sporadic cryptosporidiosis cases: first report of human infections with a cervine genotype. Emerg Infect Dis 2002;8(3):263-268
90 Leoni F, Gallimore CI, Green J, McLauchlin J. Characterisation of small double stranded RNA molecule in Cryptosporidium hominis, Cryptosporidium felis and Cryptosporidium meleagridis. Parasitol Int 2006;55(4):299-306

91 Hussain G, Roychoudhury S, Singha B, Paul J. Incidence of Cryptosporidium andersoni in diarrheal patients from southern Assam, India: a molecular approach. Eur J Clin Microbiol Infect Dis 2017;36(6):1023-1032

92 Abe N, Matsubayashi M, Kimata I, Iseki M. Subgenotype analysis of Cryptosporidium parvum isolates from humans and animals in Japan using the $60-\mathrm{kDa}$ glycoprotein gene sequences. Parasitol Res 2006;99(3):303-305

93 O'Connor RM, Wanyiri JW, Cevallos AM, Priest JW, Ward HD. Cryptosporidium parvum glycoprotein gp40 localizes to the sporozoite surface by association with gp15. Mol Biochem Parasitol 2007;156(1):80-83

94 Alves M, Matos O, Antunes F. Microsatellite analysis of Cryptosporidium hominis and C. parvum in Portugal: a preliminary study. J Eukaryot Microbiol 2003;50(Suppl):529-530

95 Ajjampur SS, Liakath FB, Kannan A, et al. Multisite study of cryptosporidiosis in children with diarrhea in India. J Clin Microbiol 2010;48(6):2075-2081

96 Xiao L. Molecular epidemiology of cryptosporidiosis: an update. Exp Parasitol 2010;124(1):80-89

97 Gatei W, Barrett D, Lindo JF, Eldemire-Shearer D, Cama V, Xiao L. Unique Cryptosporidium population in HIV-infected persons, Jamaica. Emerg Infect Dis 2008;14(5):841-843

98 Chalmers RM, Hadfield SJ, Jackson CJ, Elwin K, Xiao L, Hunter P. Geographic linkage and variation in Cryptosporidium hominis. Emerg Infect Dis 2008;14(3):496-498

99 Sulaiman IM, Hira PR, Zhou L, et al. Unique endemicity of cryptosporidiosis in children in Kuwait. J Clin Microbiol 2005;43(6):2805-2809

100 Trotz-Williams LA, Martin DS, Gatei W, et al. Genotype and subtype analyses of Cryptosporidium isolates from dairy calves and humans in Ontario. Parasitol Res 2006;99: 346-52

101 Valenzuela O, González-Díaz M, Garibay-Escobar A, et al. Molecular characterization of Cryptosporidium spp. in children from Mexico. PLoS One 2014;9(4):e96128

102 Alves M, Xiao L, Antunes F, Matos O. Distribution of Cryptosporidium subtypes in humans and domestic and wild ruminants in Portugal. Parasitol Res 2006;99(3):287-292

103 Lucca Pd, De Gaspari EN, Bozzoli LM, Funada MR, Silva SO, Iuliano W, Soares RM. Molecular characterization of Cryptosporidium spp. from HIV infected patients from an urban area of Brazil. Rev Inst Med Trop Sao Paulo 2009; 51(6):341-343

104 Bushen OY, Kohli A, Pinkerton RC, et al. Heavy cryptosporidial infections in children in northeast Brazil: comparison of Cryptosporidium hominis and Cryptosporidium parvum. Trans R Soc Trop Med Hyg 2007;101(4):378-384

105 Waldron LS, Ferrari BC, Power ML. Glycoprotein 60 diversity in C. hominis and C. parvum causing human cryptosporidiosis in NSW, Australia. Exp Parasitol 2009 ;122(2):124-127

106 Jex AR, Ryan UM, Ng J, Campbell BE, Xiao L, Stevens M, Gasser RB. Specific and genotypic identification of Cryptosporidium from a broad range of host species by nonisotopic SSCP analysis of nuclear ribosomal DNA. Electrophoresis 2007;28(16):2818-2825

107 Ng J, Eastwood K,Durrheim D, Massey P, Walker B, Armson A, Ryan U. Evidence supporting zoonotic transmission of Cryptosporidium in rural New South Wales. Exp Parasitol 2008;119(1):348-356

$108 \mathrm{Ng}$ J, MacKenzie B, Ryan U. Longitudinal multi-locus molecular characterisation of sporadic Australian human clinical cases of cryptosporidiosis from 2005 to 2008. Exp Parasitol 2010;125(4):348-356 
109 O’Brien E, McInnes L, Ryan U. Cryptosporidium GP60 genotypes from humans and domesticated animals in Australia, North America and Europe. Exp Parasitol 2008;118:118-121

110 Guyot K, Follet-Dumoulin A, Lelièvre E, et al. Molecular characterization of Cryptosporidium isolates obtained from humans in France. J Clin Microbiol 2001;39(10):3472-3480

111 Zintl A, Proctor AF, Read C, Dewaal T, Shanaghy N, Fanning S, Mulcahy G. The prevalence of Cryptosporidium species and subtypes in human faecal samples in Ireland Epidemiol Infect 2009;137(2):270-277

112 Leav BA, Mackay MR, Anyanwu A, et al. Analysis of sequence diversity at the highly polymorphic Cpgp40/15 locus among Cryptosporidium isolates from human immunodeficiency virus-infected children in South Africa. Infect Immun 2002; 70(7):3881-3890

113 Adamu H, Petros B, Zhang G, Kassa H, Amer S, Ye J, Feng Y, Xiao L. Distribution and clinical manifestations of Cryptosporidium species and subtypes in HIV/AIDS patients in Ethiopia. PLoS Negl Trop Dis 2014;8(4):e2831

114 Molloy SF, Tanner CJ, Kirwan P, et al. Sporadic Cryptosporidium infection in Nigerian children: risk factors with species identification. Epidemiol Infect 2011;139(6):946-954

115 Alyousefi NA, Mahdy MA, Mahmud R, Lim YA. Factors associated with high prevalence of intestinal protozoan infections among patients in Sana'a City, Yemen. PLoS One 2011;6(7):e22044

116 Nyamwange CI, Mkoji G, Mpoke S, Nyandieka HS. Cryptosporidiosis and its genotypes among children attending MOI teaching and referral hospital in Eldoret, Kenya. East Afr Med J $2012 ; 89(1): 11-19$

117 Iqbal J, Khalid N, Hira PR.Cryptosporidiosis in Kuwaiti children: association of clinical characteristics with Cryptosporidium species and subtypes. J Med Microbiol 2011;60(Pt 5):647-652

118 Rao Ajjampur SS, Asirvatham JR, Muthusamy D, et al. Clinical features \& risk factors associated with cryptosporidiosisin HIV infected adults in India. Indian J Med Res 2007;126(6):553-557

119 Yadav P, Khalil S, Mirdha BR. Molecular appraisal of intestinalparasitic infection in transplant recipients. Indian J Med Res 2016;144(2):258-263

120 Das P, Roy SS, MitraDhar K, et al. Molecular characterization of Cryptosporidium spp. from children in Kolkata, India. J Clin Microbiol 2006;44(11):4246-4249

121 Del Chierico F, Onori M, Di Bella S, et al. Cases of cryptosporidiosis co-infections in AIDS patients: a correlation between clinical presentation and GP60 subgenotype lineages from aged formalin-fixed stool samples. Ann Trop Med Parasitol 2011;105(5):339-349 